\title{
Del Nihilismo al pUnto de VISta. Ecosistema CUltural de la Argentina ReCiente ${ }^{1}$
}

\author{
Ignacio Ramírez ${ }^{2}$
}

Resumen: ¿Cuáles son los rasgos distintivos de "los años kirchneristas"? El autor propone pensar el kirchnerismo en clave de época, para lo cual presenta un conjunto de datos y de reflexiones que bosquejan una caracterización de la cultura política de la Argentina reciente. Sostiene que en cada etapa histórica existe cierta correspondencia entre el rumbo político del plano político e institucional y el clima dominante de valores que respira la sociedad. $\mathrm{Al}$ respecto, la tesis del artículo sostiene que el kirchnerismo ha sido causa y consecuencia de un nuevo ecosistema cultural, cuya marca más destacada ha sido la (re)politización de los argentinos. Como aporte en materia de conocimiento empírico del período, el autor reúne fragmentos de distintos estudios realizados entre Ibarómetro y Flacso, que ilustran los vínculos entre los argentinos y la política, signados por la efervescencia y el debate.

Palabras clave: politización, cultura política, kirchnerismo, nihilismo

Abstract: What are the distinctive features of the "kirchnerists years"? The author suggests thinking the kirchnerism in terms of an age, so he presents a gathering of data and ideas that draw

$1 \quad$ Quisiera agradecer especialmente a Luis Alberto Quevedo por sus enseñanzas sobre cultura y política, y los aportes al trabajo de Guido Moscoso y de Julián Libonatti, integrantes de Ibarómetro.

2 Sociólogo (Universidad de Buenos Aires) con Posgrado en Comunicación, Política y Cultura (Universidad Complutense de Madrid). Director de Ibarómetro y coordinador académico del Posgrado en Opinión Pública de Flacso Argentina. Contactos: iramirez@ibarometro.com y@nachoram. 
a characterization of the political culture in the recent years in Argentina. The author states that each historical age has some correspondence between the political direction of the political and institutional areas and the dominant value environment within the society. Thus, the thesis in the article states that the kirchnerism has been cause and consequence of a new cultural ecosystem, whose most significant landmark has been the (re) politization of the Argentineans. As a way of adding empirical knowledge to the period, the author gathers fragments of different researchs carried out by Ibarómetro and Flacso. These illustrate the bonds between the Argentineans and politics, marked by effervescence and debate.

Key words: nihilism, political culture, kirchnerismo, politicization

\section{Introducción}

El presente artículo tiene un objeto y un objetivo. Su objeto son "los años kirchneristas" y su objetivo principal radica en describir - $i$ demostrar?- un proceso de politización que ha experimentado la sociedad argentina en el curso de los últimos años.

En líneas generales, los análisis sobre el kirchnerismo han estado obsesivamente centrados en la oferta, los liderazgos, la dirigencia y las políticas implementadas. Toda mirada es inevitablemente excluyente: ilumina aspectos de la realidad que aspira a capturar pero al mismo tiempo, por estar orientada, oscurece aquellos rincones que quedan marginados del campo visual. Lo que ha permanecido ignorado en los debates políticos y académicos respecto a la caracterización del kirchnerismo ha sido la sociedad. Este trabajo no se propone descifrar la esencia ideológica, ni reconstruir las raíces identitarias del espacio político que gobierna la Argentina desde 2003. La intencionalidad que anima las siguientes páginas consiste en reorientar 
la mirada hacia el clima cultural que ha enmarcado los últimos doce años de la Argentina, "los años kirchneristas".

El paso del tiempo nos permite, y al mismo tiempo nos exige, reflexionar con mayor serenidad y mejor perspectiva sobre el kirchnerismo en clave de época. El empleo de la expresión "clave de época" apunta al siguiente argumento: cuando hablamos sobre el menemismo no aludimos, únicamente, a un gobierno o a un conjunto de políticas públicas, sino que invocamos una particular atmosfera ideológica, una singular textura cultural que transpiraron aquellos tiempos. El kirchnerismo es, también, una época y en consecuencia merece ser abordado desde esa perspectiva. Ahí vamos.

\section{Navegaciones conceptuales}

Resultan necesarias algunas consideraciones sobre el instrumento del cual surgen los datos que estructuran el texto, las encuestas de opinión pública, y sobre el enfoque del cual están impregnadas las conceptualizaciones que se irán desplegando: la interpretación de los datos como observables o signos de la cultura política de los argentinos.

Las encuestas, al menos las de mayor circulación periodística, suelen estar sometidas a la tirana y epidérmica intermitencia de la coyuntura. Pero las coyunturas, como hoja de ruta para comprender fenómenos sociales, suelen resultar engañosas ya que nos ubican en una perspectiva desde la cual, como si tuviéramos una lupa mal calibrada, sobredimensionamos cambios en la superficie de "nuestra piel social", y quedan ocultos continuidades y patrones subyacentes más arraigados y menos zigzagueantes.

Para evitar tal riesgo, quisiera recuperar el espíritu de los estudios clásicos de cultura política, cuyas producciones desde sus orígenes han intentado eludir el ruido de la coyuntura para examinar el clima de valores y de actitudes 
que singulariza una determinada etapa histórica. Una de las tesis centrales que recorre los trabajos sobre cultura política es aquella según la cual existe cierta correspondencia entre lo que ocurre en el plano más visible de la vida política e institucional de una sociedad y lo que sucede en su anatomía interna de creencias, matrices culturales y orientaciones ideológicas. Al aterrizar esta noción sobre el escenario sociopolítico argentino, defino con contornos más precisos la tesis principal de este artículo: el kirchnerismo constituye una especial atmósfera cultural e ideológica, mucho más abarcativa y estable que los cambiantes niveles de aprobación que la gestión de gobierno puede suscitar en diferentes circunstancias. Resulta una operación plagada de faltas y de ausencias pensar el kirchnerismo sin atender a su dimensión cultural, sin calibrar los valores que se han sedimentado sobre la cultura política de los argentinos en el curso de los últimos años, marcados por la intensidad y el desacuerdo, es decir, marcados por la política. En una entrevista reciente concedida a medios internacionales, ${ }^{3}$ el líder de Podemos, Pablo Iglesias, formula dos elocuentes comentarios sobre la Argentina. Por un lado confiesa que nunca ha visitado el país más que como pasajero en tránsito hacia otros destinos latinoamericanos. Sin embargo, sostiene que "en la Argentina se habla de política por todos lados". Esto es, Pablo Iglesias, pese a no disponer de experiencias directas, apunta sobre uno de los rasgos que distinguen la escena pública de la Argentina contemporánea: su efervescencia.

El aporte del presente artículo radica en reunir un conjunto de evidencia empírica ${ }^{4}$ a través de la cual puedan

Nota publicada por el diario argentino La Nación. Disponible en: http:// www.lanacion.com.ar/1768331-pablo-iglesias-el-peronismo-nos-resulta-extraterrestre-en-europa.

4 Los estudios de los cuales surgen los datos contenidos en el presente artículo integran el proyecto "Cultura política de los argentinos" dirigido por Luis Alberto Quevedo e Ignacio Ramírez en el marco de un trabajo 
ponerse en perspectiva y juzgarse las observaciones sobre nuestra supuesta (re)politización.

El texto estará fundamentalmente apoyado -después de algunas páginas donde las protagonistas serán las palabras y no los porcentajes- en resultados de distintos estudios que venimos realizando desde Ibarómetro y Flacso Argentina. En conjunto, hemos decidido iniciar una serie de estudios sistemáticos orientados a describir las actitudes políticas de los argentinos y, a su vez, a monitorear su evolución. Para ello se han realizado cinco mediciones desde el año 2010 compuestas por indicadores de actitudes y de participación política, muchos de ellos utilizados habitualmente por el Centro de Investigaciones Sociológicas de España. Las mediciones acumuladas desde el inicio del proyecto nos han permitido conocer mejor los vínculos y las miradas de los argentinos en torno a la política. A los objetivos descriptivos, que serán satisfechos a través de fragmentos de tales relevamientos, se añade un propósito que aspiro cumplir: aportar una serie de insumos empíricos que colaboren con un abordaje más "epocal" de los años recientes de la Argentina. Uno de los hallazgos principales de tales estudios reside en un parcial proceso de politización que experimenta el país, a contramano de lo indicado por una vasta bibliografía que viene insistiendo en la desafección política como rasgo distintivo del horizonte contemporáneo.

En relación con las narrativas sobre despolitización, resulta interesante recordar que hace pocos años, la agenda mainstream de la Ciencia Política estaba obsesivamente concentrada en lo que el sociólogo francés Pierre Ronsavallon calificó como "el sonsonete de la desafección" (Rosanvallon, 2007). Un ejército de papers y libros anunciaban la configuración de una ciudadanía abúlica, 
individualizada y completamente de espaldas a la arena política. En su brillante libro Bowling Alone, Robert Putnam (2002) lamentaba, con cierta melancolía, que el paisaje ciudadano estaba siendo invadido por "babosas cívicas". Aquel tejido participativo que había fascinado a Toqueville en su visita a Estados Unidos estaría siendo sustituido por una anémica vida asociativa. Los espacios de socialización y de participación van quedando desiertos, sin ofrecernos otra alternativa más que jugar solos al bowling (aquí traduciríamos al "papi futbol"). En una dirección argumental similar, y con un análisis de mayor alcance en el tiempo, Richard Sennet consignó hace algunos años una tendencia irreversible: el declive del hombre público (Sennet, 1978).

Lo cierto es que en la actualidad la agenda de las Ciencias Sociales y sobre todo el menú de sus seminarios están crecientemente poblados por trabajos sobre modalidades de protesta, participación política juvenil y primaveras de acción colectiva. Síntomas de que algo ha cambiado. Sobre ese cambio nos ocuparemos aquí, tratando de ofrecer un bosquejo del nuevo ecosistema cultural argentino, aquel que ha reemplazado nihilismo por punto de vista y desafección por politización.

Volvamos al concepto de cultura política. Las encuestas no constituyen el único ni necesariamente el mejor camino para caracterizar la cultura política de una sociedad. Tres ejemplos son suficientes para demostrarlo: La democracia en América de Alexis de Tocqueville, el Facundo de Domingo Faustino Sarmiento y iY a mí qué mierda me importa? de Guillermo O囚Donnell, son brillantes piezas de cultura política que difícilmente puedan ser superadas por trabajos dotados de datos de encuestas y regresiones.

De cualquier manera, las encuestas revelan aspectos importantes de nuestra piel social y, cuando se lo intenta, también pueden alumbrar el subsuelo de valores que se esconden en el sótano de la opinión pública. Opinión pública 
y cultura política son conceptos fronterizos y, por lo tanto, habitualmente confundidos. Propongo una esquemática distinción: la opinión pública representa la cara visible y epidérmica de la sociedad; de allí que la metáfora de NoelleNeumann (1995) resulte tan operativa. Y por debajo de la piel funciona una anatomía interior de valores y actitudes, profundas y más estables, que no reaccionan histéricamente ante cada ruidosa noticia de los medios. Al hablar del subsuelo de valores y actitudes me refiero a la cultura política.

El concepto de cultura política fue definido por Gabriel Almond y Sidney Verba (1965) en su obra fundacional The Civic Culture. Allí los autores proponen una definición capaz de ser aterrizada empíricamente de manera de habilitar mediciones y comparaciones. Se trataba de un concepto que navegaba en territorios románticos cercanos a la idea del "ser nacional". Una de las virtudes de la obra consistió en rescatar el concepto de cultura política del naufragio metafísico y trasladarlo a un enfoque centrado en la generación de evidencia empírica, menos contaminado de los folclores nacionales. Otra de las valiosas innovaciones contenidas en The Civic Culture radicó en el empleo de metodologías cuantitativas -encuestas-, como instrumentos capaces de caracterizar las distintas culturas políticas que singularizan determinadas sociedades o comunidades. Desde la difusión de la obra se ha acumulado un conjunto de estudios y de reflexiones que, si bien plantean críticas a la obra de Almond y Verba, reconocen en ella la inauguración de una tradición teórico-metodológica con la cual el presente artículo mantiene visibles deudas.

En la Argentina, las Ciencias Sociales han lucido históricamente cierta resistencia al conductismo y al funcionalismo que suelen distinguir la investigación americana. Este rasgo de la gestualidad intelectual argentina desalentó durante mucho tiempo la realización de estudios políticos mediante encuestas, lo que generó un déficit de datos que 
afortunadamente se ha venido reparando en los últimos tiempos. Una de los efectos más dañinos de la tardía llegada de esta tradición a la Argentina radica en la escasez de publicaciones sobre cultura política de los argentinos, basadas en mediciones empíricas. La Argentina bipolar de Mora y Araujo convive con Los argentinos y la política de Edgardo Catterberg casi en soledad en ese estante de las librerías.

Con respecto al libro La Argentina bipolar, dotado de una valiosa y frondosa cantidad de datos surgidos de encuestas, me tomaré la irreverencia de objetar algunas tesis defendidas por su autor. Mora y Araujo (2011) describe alteraciones en las orientaciones ideológicas de los argentinos quienes, por ejemplo, modificaron su perspectiva mayoritaria en relación con el rol del Estado. A tales cambios los envuelve semánticamente bajo la idea de "bipolaridad", imagen que nos desliza al universo de las patologías psíquicas. Estirando, y seguramente deformando, los planteos del maestro, el libro sugiere que los cambios observados serían caprichosos, irracionales, lo cual acreditaría la existencia de una opinión pública sinuosa e imprevisible. Desde nuestra perspectiva, y con menos credenciales para desafiar las reflexiones de Mora y Araujo, los cambios operados no deben ser leídos como irracionales. Para discutir la tesis de la bipolaridad estableceré alianzas con Albert Hirschmann, Benjamin Page y Robert Shapiro.

Albert Hirschman escribió que las sociedades alternan períodos más replegados sobre lo privado, impregnados por valores individualistas y distinguidos por una débil pulsión participativa, con otros períodos signados por el resurgimiento de lo público y de lo colectivo. Tales categorías, combinadas con los datos que compartiremos, nos permitirán más adelante esbozar la imagen de una sociedad que ha puesto un pie en el segundo de los ciclos. De acuerdo con Hirschman, el Zeitgeist epocal, regido por una particular distribución de centralidad en el eje 
privado-publico, es pendular; el mecanismo oculto que lo hace funcionar es la neurótica insatisfacción de los seres humanos, quienes por momentos se acercan a la satisfacción por canales privados pero, una vez enfrentados con el desencanto y el vacío, salen a la esfera pública en busca del mismo beneficio: satisfacción y sentido para la vida. Pero, fatalmente, vuelven a sentirse insatisfechos... y el péndulo invierte su dirección (Hirschman, 1986).

Con relación a Page y Shapiro, es conocida su militante defensa a favor de la racionalidad de los cambios que experimenta la opinión pública. Los autores sostienen que los cambios de la opinión pública son racionales y, en buena medida previsibles, ya que obedecen a transformaciones del entorno y a modificaciones en la información disponible sobre los distintos temas que movilizan sus opiniones (Page y Shapiro, 2013).

Desde esta perspectiva, podríamos pensar que la agresiva experiencia directa de los argentinos vinculada con el deterioro de su entorno sociolaboral, agudizado en la década de 1990, provocó un proceso de revisión crítica de los valores que habían sostenido la legitimidad simbólica del programa menemista. Las políticas que resumiremos con la expresión "Reforma del Estado", expresión cara a la matriz política dominante de aquellos años, sólo fueron posibles en la medida en que fueron acompañadas por generalizadas visiones negativas respecto a lo público, al Estado y a la política. Estos tres ámbitos componen un triángulo de valores que se reducen o se fortalecen de manera solidara y paralela. Como veremos más adelante, en los últimos años, el triángulo actitudinal "público, Estado y política" se ha fortalecido. Es imposible saber si se consolidó para siempre o si, por el contrario, el péndulo de Hirschman retomará su viaje hacia el hemisferio privatizado.

En cualquier caso, ya sea por la endógena insatisfacción humana, muy humana, o por el resultado tangible de crisis 
asociadas con determinadas cosmovisiones y políticas, los cambios no se nos deberían presentar como irracionales o como rotaciones de una caprichosa bipolaridad.

\section{Argentinos, a las cosas: presentación de resultados}

$\mathrm{Al}$ inicio del trabajo formulé una serie de planteos: en primer lugar sostuve la necesidad de pensar los años kirchneristas en clave de época. Tal perspectiva me condujo a sostener la presencia -anunciada en el título del trabajode un nuevo ecosistema cultural argentino. Asimismo, en distintos fragmentos de las páginas iniciales, afirmé que uno de los rasgos distintivos de ese paisaje sociopolítico reside en un proceso de creciente politización de la sociedad argentina. El resto del trabajo estará dedicado a presentar diferentes resultados de estudios que ilustran empíricamente tales conceptualizaciones.

En anteriores intervenciones ${ }^{5}$ presenté una caracterización del actual ecosistema cultural estructurado en tres dimensiones, articuladas entre sí:

1. Politización

2. Consenso ideológico

3. Nuevo consumo de medios

En este artículo me concentraré en las proporciones, las tendencias y los rasgos que tal politización adquiere en la sociedad argentina. No recibirán tratamiento los puntos dos y tres; sin embargo me gustaría sobrevolar sus elementos más destacados.

La tesis del consenso ideológico puede resultar provocadora a luz de la insistente "teoría de la grieta" como representación de una sociedad fracturada. Sin embargo, distintos estudios han revelado un conjunto de vectores

Se desarrolló el tema en Capurro y Ramírez (2011). 
ideológicos que suscitan una amplia adhesión y sobre los que se edifica el clima discursivo dominante de los años kirchneristas. Las tres coordenadas más destacadas de este consenso son: una mayoritaria inclinación por un rol activo del Estado, una conceptualización de la democracia asociada a la búsqueda de mayor equidad y la preferencia a favor de alianzas económicas y políticas con países de la región. ${ }^{6}$

Con la expresión "nuevo consumo de medios" ${ }^{7}$ apunto hacia otro aspecto que las encuestas han podido relevar: una generalizada visión de los medios de comunicación ya no como testigos asépticos de la realidad, sino como actores teñidos de inclinaciones ideológicas y/o de intereses económicos. A este fenómeno lo he llamado "el fin de la inocencia", una sociedad con sus músculos críticos más entrenados a la hora de exponerse a la información y a los encuadres que ofrecen los medios de comunicación. En suma, ha entrado en crisis la neutralidad narrativa y por ello he elegido la idea de "punto de vista" para definir al pathos del ecosistema que nos envuelve.

\section{Politización $^{8}$}

Examinar los niveles de politización de los ciudadanos admite distintos recorridos. A la hora de conocer el interés político de los ciudadanos se nos presentan dos alternativas: una directa y otra indirecta. El camino directo

Presento resultados para las adhesiones referidas en "Los mapas y el territorio" (Le Monde Diplomatique, julio de 2013).

7 Puede consultarse un desarrollo más amplio en Ramírez (2013).

8 Los datos incluidos en el capítulo surgen de una encuesta telefónica de alcance nacional, realizada entre el 20 y el 25 de julio de 2014 y basada en una muestra de carácter representativo. El estudio fue realizado por Ibarómetro y Flacso Argentina y dirigido por Luis Alberto Quevedo e Ignacio Ramírez. 
consiste en aplicar la pregunta “ ¿Usted diría que la política le interesa mucho, bastante, poco o nada?", que recoge el interés político declarado por los encuestados. El sendero más sinuoso surge de observar algunos hábitos de los que podamos deducir un interés político subyacente.

Planteo el siguiente ejemplo para graficar el segundo camino: si un amigo nos cuenta que todos los domingos asiste a la cancha a ver un partido de fútbol sería innecesario preguntarle si le interesa el fútbol puesto que su interés se encuentra implícito en los cimientos de su rutina dominguera. Es posible, también, espiar indirectamente el interés político de los ciudadanos conociendo algunos de sus hábitos. Vemos los resultados de las dos rutas transitadas.

Consultados acerca del grado de interés que les despierta la política, un $52 \%$ de los entrevistados manifestó que les interesa "mucho" o "bastante", mientras que el $45 \%$ declaró "poco" o "nada" de interés por la política.

\section{Gráfico 1}

Frecuencia de interés político declarado

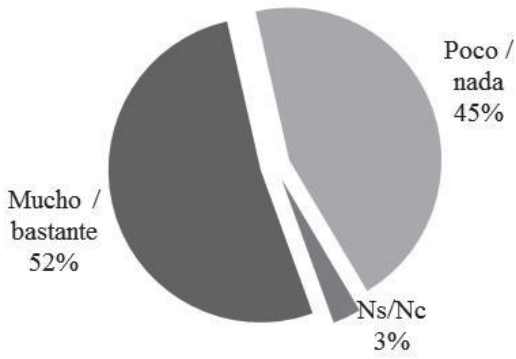

Fuente: elaboración propia en base a la "Encuesta Cultura Política en Argentina” (Ibarómetro-Flacso, 2014).

$\mathrm{Al}$ recorrer el sendero indirecto, observar hábitos de politización subyacente, los resultados son los siguientes: 


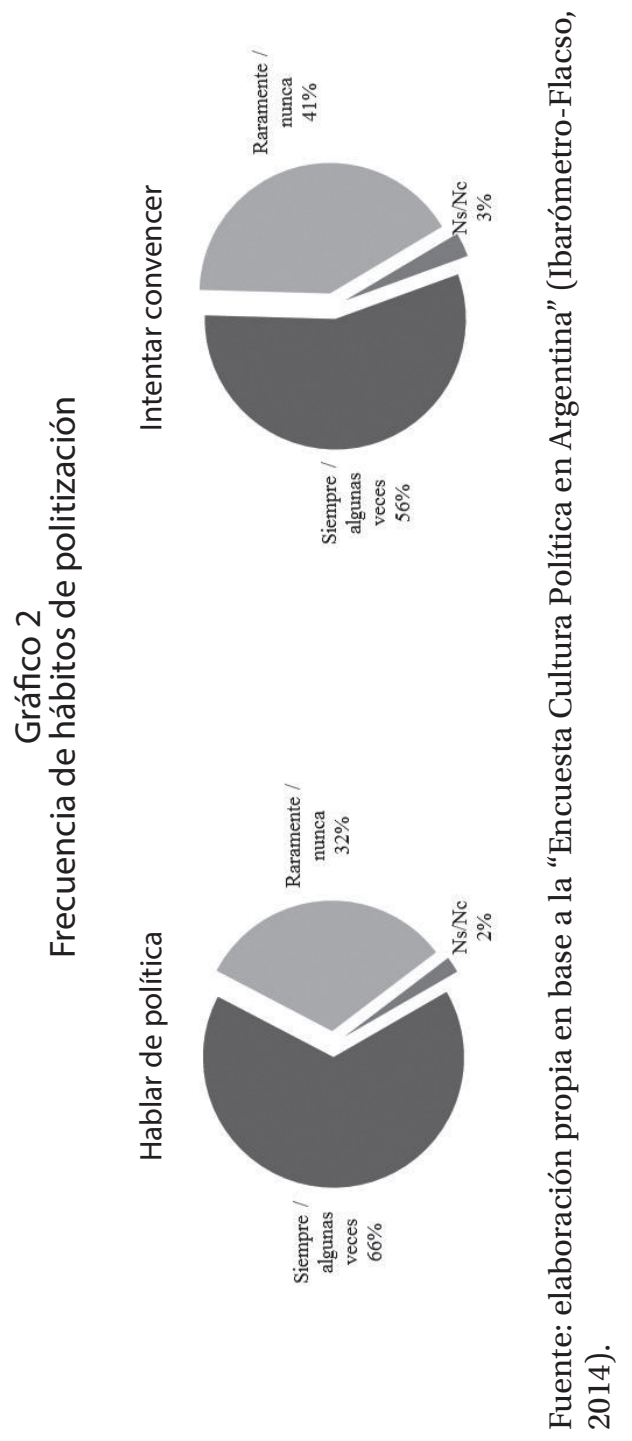


Si bien los resultados observados en el indicador "interés político declarado" permitirían advertir una extendida proximidad entre los argentinos y la política, al examinar el desempeño de dos variables relativas a los hábitos políticos de los argentinos se observa que los vínculos ciudadaníapolítica poseen incluso un carácter de mayor magnitud y densidad. El indicador referido a la práctica de persuasión política capilar reviste especial importancia ya que ilustra un aspecto más cualitativo del fenómeno. El dato según el cual el $56 \%$ de los argentinos intenta convencer a sus conocidos sobre sus opiniones desnuda una extendida actitud militante; revela que la politización de los argentinos no constituye un hecho restringido al plano cognitivo (interés temático-informativo) sino que comporta una intensa implicación afectiva y/o ideológica.

La escasa distancia entre el porcentaje de quienes conversan sobre política y el de quienes, al hacerlo, debaten marcados puntos de vista ayuda a capturar la textura de la conversación política en la Argentina. Provee, al mismo tiempo, insumos para bosquejar respuestas ante interrogantes como los siguientes: ¿en qué hábitos se traduce estar interesado en política? ¿Cómo se conversa sobre política en una determinada sociedad, en un determinado contexto histórico-político?

Los datos parecieran respaldar la tesis de que en Argentina las conversaciones de los ciudadanos sobre política adquieren los rasgos de un debate, a la luz del extendido hábito de intentar convencer a los contertulios sobre las opiniones expuestas. Un entramado infinito de diálogos cuyo contenido principal pareciera ser más la identificación con alguna posición política que el comentario aséptico. En función de esta interpretación, hemos conceptualizado al dato como el signo de una extendida actitud militante en la sociedad argentina. Debería analizarse con mayor detenimiento, pero la "actitud militante" 
podría ser encuadrada como una modalidad capilar de participación política.

Con el objeto de pasar en limpio y de compaginar los matices del interés por la política expuestos, introduciré una nueva variable resumen: "Segmentación de interés por la política". El nuevo indicador, al conjugar el interés político declarado y los dos hábitos políticos medidos, permite conocer mejor el alcance y la distribución del interés político que existe entre los diferentes segmentos que componen la sociedad argentina.

La arquitectura de la segmentación es muy sencilla:

1. Las tres variables que la integran ("interés político declarado", "frecuencia conversa sobre política" y "frecuencia intenta convencer") fueron dicotomizadas y codificadas en "1", valor que reúne las dos categorías más altas (siempre/ algunas veces o mucho/bastante) y en "0", valor que agrupa las categorías más bajas (raramente/nunca o poco/nada).

2. Luego, en la nueva variable "segmentación de interés por la política", cada entrevistado recibió la suma de su puntuación en las tres variables.

3. La nueva variable quedó codificada en cuatro categorías correspondientes a las cuatro posibles puntuaciones que puede recibir cada encuestado: "0: muy bajo interés político"; "1: bajo interés"; “2: alto interés"; y "3: muy alto interés". Veamos los resultados: 


\section{Gráfico 3}

Segmentación de interés por la política

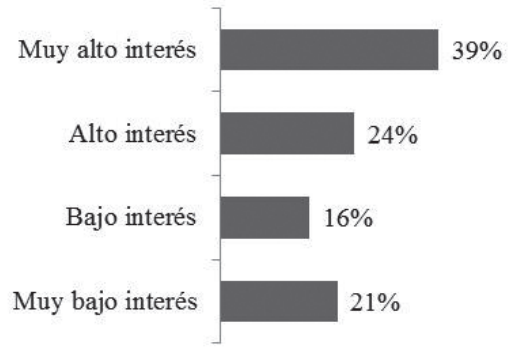

Fuente: elaboración propia en base a la "Encuesta Cultura Política en Argentina” (Ibarómetro-Flacso, 2014).

Los resultados acreditan que el interés por la política constituye un fenómeno mayoritario en la población argentina. Un 39\% demuestra un "muy alto interés", acompañado por un $24 \%$ de encuestados que lucen "alto interés". En condición de minoría, un $16 \%$ queda clasificado como "bajo interés", mientras que el $21 \%$ de los argentinos estaría completamente desprovisto de interés político. Los datos proyectan la imagen de una atmósfera discursiva teñida de política.

Si bien los valores globales revelan una generalizada politización, toda presentación agregada de una variable esconde contrastes interiores. A continuación el foco estará puesto en la distribución del interés por la política, considerando diversas variables de segmentación. La Tabla 1 muestra la distribución recodificada del "índice de interés por la política” según variables sociodemográficas como género, edad y nivel educativo. Se incorpora al análisis una variable relativa al posicionamiento político: la "imagen del gobierno nacional". Además del interés descriptivo por conocer los distintos niveles de politización, los cruces 
entre variables contienen también beneficios explicativos puesto que habilitan la detección de aquellos factores más o menos asociados con, en este caso, el grado de politización de los ciudadanos.

Tabla 1

Segmentación de interés por la política según género, edad, nivel educativo e imagen del Gobierno nacional (en \%)

\begin{tabular}{|c|c|c|c|c|c|c|c|c|c|c|c|}
\cline { 2 - 11 } \multicolumn{1}{c|}{} & \multirow{2}{*}{ Total } & \multicolumn{2}{|c|}{ Género } & \multicolumn{4}{c|}{ Edad } & \multicolumn{3}{c|}{ Nivel educativo } & $\begin{array}{c}\text { Imagen } \\
\text { del } \\
\text { Gobierno } \\
\text { nacional }\end{array}$ \\
\cline { 2 - 11 } & & Masc. & Fem. & $\begin{array}{c}16 \text { a } \\
30\end{array}$ & $\begin{array}{c}31 \text { a } \\
50\end{array}$ & $>50$ & Bajo & Medio & Alto & Pos. & Neg. \\
\hline $\begin{array}{c}\text { Muy alto } \\
\text { interés + } \\
\text { alto interés }\end{array}$ & 63 & 67 & 60 & 60 & 65 & 65 & 56 & 63 & 75 & 70 & 63 \\
\hline $\begin{array}{c}\text { Bajo interés } \\
+ \text { muy bajo } \\
\text { interés }\end{array}$ & 37 & 33 & 40 & 40 & 35 & 35 & 44 & 37 & 25 & 30 & 37 \\
\hline
\end{tabular}

Fuente: elaboración propia en base a la "Encuesta Cultura Política en Argentina” (Ibarómetro-Flacso, 2014).

La Tabla 1 permite reconocer que el interés por la política es un fenómeno altamente difundido en todos los diversos segmentos que integran la sociedad argentina; en todos los sectores analizados el interés por la política supera, por amplio margen, el desinterés. Sin dejar de tener en cuenta este carácter, es necesario detallar algunas interesantes variaciones reflejadas en la tabla: a mayor nivel educativo se acentúa el interés por la política, correlación ampliamente documentada por todos los trabajos sobre estos temas. Asimismo, los hombres demuestran mayor interés por la política que las mujeres; asimetría que anida en la historia cultural de las representaciones sobre género 
y espacio público. Los adultos se muestran ligeramente más interesados por la política que los jóvenes aunque la diferencia es muy poco pronunciada. Por último, una imagen positiva del Gobierno nacional exhibe una correlación positiva con el interés político.

Dada la centralidad que ha adquirido en la discusión política argentina el vínculo entre juventud y política considero necesario hacer un zoom en este aspecto.

Los jóvenes han sido recurrentemente señalados como apáticos y de espaldas a cualquier inquietud de carácter pública. Para enmarcar el tema volveré a Bowling Alone, libro de central importancia en el conjunto más visitado de investigaciones sobre cultura política. En aquel texto, Putnam describe y analiza el deterioro del compromiso cívico de los ciudadanos y la forma en que el capital social de la sociedad norteamericana se ha ido encogiendo e insularizando. Su libro pretende identificar a los "asesinos" del compromiso comunitario. Entre los distintos culpables que identifica, Putnam le imputa la mitad de los cargos a "la parca", fúnebre expresión con la que alude al recambio generacional. Después de aportar distintos testimonios sobre el declive del capital social, el autor sostiene que la renovación generacional "se trata de un factor que podría explicar quizá la mitad del declive total" (Putnam, 2002: 373).

Al volver a nuestros datos -seis de cada diez jóvenes en la argentina manifiestan niveles altos de interés político- es posible establecer que la parca de Putnam no parece estar haciendo en Argentina el mismo trabajo que el autor le atribuye en Estados Unidos. Puede conjeturarse que los jóvenes socializados durante los años kircheristas han sido contagiados por las marcas de la politización reinante en el nuevo ecosistema cultural vigente. 


\section{Eficacia política interna}

En este apartado me ocuparé de un conjunto de actitudes políticas a las que la literatura politológica denomina "eficacia política". Las actitudes políticas constituyen orientaciones adquiridas que, gozando de un relativa estabilidad, inciden directamente en el comportamiento político (Anduiza y Bosch, 2009). La literatura sobre actitudes políticas suele considerar dos perspectivas generales en torno a esta dimensión. Por un lado, las actitudes relacionadas con la eficacia política del sistema, relativas a su receptividad percibida, son definidas como "eficacia política externa". Por otra parte, aquellas actitudes de los ciudadanos directamente relacionadas con la implicación política, y que refieren a sus representaciones respecto del rol que cumplen o son capaces de cumplir dentro del sistema político. La eficacia política interna (EPI) concierne a las competencias cívicas autopercibidas por los propios ciudadanos para comprender e intervenir en la esfera pública. Los próximos párrafos estarán dedicados a exponer resultados sobre los niveles de EPI que lucen los argentinos, expresados con una incógnita: ¿qué grado de potencia ciudadana se atribuyen a sí mismos?

La indagación empírica mediante estudios cuantitativos acostumbra abordar esta dimensión consultando el grado de acuerdo o de desacuerdo de los encuestados ante distintas afirmaciones. A fines de explorar el comportamiento de este aspecto, hemos operacionalizado el concepto de "eficacia política interna" en tres indicadores. El paso siguiente consiste en medir la adhesión o el rechazo que suscitan tres afirmaciones que condensan determinadas conceptualizaciones y actitudes frente a la política: "la política tiene una gran influencia en la vida de cualquier ciudadano"; "en general me considero un ciudadano que entiende de política"; y "la gente como yo no tiene ninguna 
influencia sobre lo que hace el gobierno". A continuación se presentarán los resultados obtenidos para este continente de la cultura política.

\section{Gráfico 4}

Nivel de acuerdo con distintos indicadores de eficacia política interna

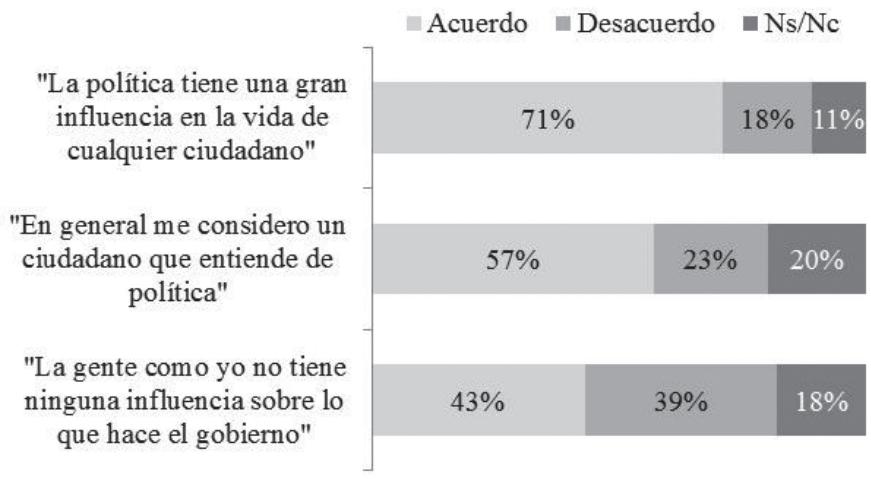

Fuente: elaboración propia en base a la "Encuesta Cultura Política en Argentina” (Ibarómetro-Flacso, 2014).

La afirmación "la política tiene una gran influencia en la vida de cualquier ciudadano" es, de las relevadas, la que mayor consenso despierta entre los encuestados. Un $71 \%$ se muestra de acuerdo con esa frase mientras que sólo un $18 \%$ se pronuncia en desacuerdo. Expresado en un lenguaje más coloquial, los argentinos perciben que la política "no está en otra parte", sino que constituye una arena cuyo desarrollo produce efectos vinculantes sobre sus biografías, sobre la calidad del cotidiano. En segundo lugar, un $57 \%$ suscribe a la frase "en general me considero un ciudadano que entiende de política” mientras que un $23 \%$ se declara desprovisto de esas competencias. La mayoría 
de los argentinos, entonces, no percibe a la política como una película guionada de manera indescifrable, sino que más bien la mira como una trama cuya estructura es capaz de analizar y comprender.

La afirmación en la que se observa mayor heterogeneidad de respuestas es en "la gente como yo no tiene ninguna influencia sobre lo que hace el gobierno": un $43 \%$ se muestra de acuerdo y un $39 \%$ en desacuerdo. Si bien aparecen empatadas las proporciones de agencia e impotencia política, casi el $40 \%$ de ciudadanos que se considera capaz de incidir en el destino político constituye un umbral comparativamente alto para una variable de tanta exigencia. Sin duda, el amplio abanico de modalidades de protesta y de participación que ha hecho de la Argentina un caso de estudio y un exportador de formatos y consignas de acción colectiva, ha contribuido a entrenar los músculos cívicos de los argentinos.

En conjunto, los datos sobre eficacia política revelan que el nihilismo no es la nota dominante de la melodía política que suena en la Argentina, donde la mayoría de sus ciudadanos se consideran capaces de volcar sus puntos de vista y sus demandas sobre el sistema político.

\section{Nihilismo político}

El presente apartado reúne un único dato que pese a su soledad resulta central en la argumentación desplegada desde el inicio del texto, desde el título que lo inaugura. De acuerdo con la perspectiva en la que se enrola este artículo, el dato más revelador de las transformaciones en el Zeitgeist que respiramos y transpiramos radica en esta variable a la que he bautizado "nihilismo político". Sin involucrarme en disquisiciones filosóficas, definiré "nihilismo político" como aquella creencia y/o percepción según la cual "todos 
los políticos son iguales". El siguiente gráfico presenta las opiniones de los argentinos en relación con este punto.

\section{Gráfico 5}

Nivel de acuerdo con la afirmación

"todos los políticos son iguales"

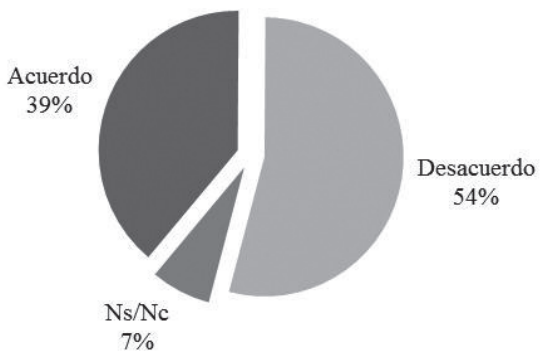

Fuente: elaboración propia en base a la "Encuesta Cultura Política en Argentina” (Ibarómetro-Flacso, 2014).

La mayoría de los argentinos no luce síntomas agudos de nihilismo político, lo cual constituye un dato novedoso en relación con el punto de partida imaginario desde el cual se ha ido configurando el nuevo ecosistema cultural argentino. Me refiero a la crisis de representación que estalló en las calles en aquel diciembre de 2001.

Si bien no disponemos de datos para el año 2001 o el año 2002, y no podemos rebobinar la historia, me permito conjeturar con alta "sensación de confianza" que formulada hace diez años la misma pregunta reclutaría volúmenes de nihilismo político muy superiores a los observados en este trabajo. En reemplazo de encuestas, recordemos algunas consignas de aquellos meses: "que se vayan todos" y "son todos lo mismo" condensaron la mirada mayoritaria, agudamente escéptica, que tenía la sociedad argentina hacia la superestructura de representación, especialmente la del 
ámbito político. Se trata de un núcleo actitudinal central en el vínculo entre sociedad y política, expresado en el más o menos generalizado descreimiento hacia lo que el lenguaje periodístico denomina "la clase política".

He decidido dedicar un tratamiento especial a esta variable al considerarla constitutiva de los fenómenos de apatía ciudadana que se observan en muchas democracias contemporáneas, cuya expresión más crítica emerge con la creciente abstención electoral -observada en sociedades como la de Francia, la de Colombia, la de Chile, entre otras- que lesiona la legitimidad, ya no de gobiernos, sino del sistema político en su conjunto.

Visitemos nuevamente los resultados: la postura nihilista es minoritaria en la sociedad argentina. Un $54 \%$ de los encuestados rechaza la idea según la cual todos los políticos son iguales mientras que un $39 \%$ se muestra de acuerdo.

$\mathrm{Al}$ analizar los resultados según género, edad, nivel educativo e imagen del Gobierno nacional se detectan diferencias importantes. Los encuestados que poseen una imagen negativa del Gobierno nacional y los de un bajo nivel educativo tienden, en mayor proporción, a manifestar niveles más altos de "nihilismo político". Un hallazgo interesante, y tal vez contraintuitivo, radica en los jóvenes, segmento que luce niveles de descreimiento comparativamente más bajos que los de sus hermanos mayores y los de sus padres. Nuevamente los resultados sobre los jóvenes desinflan muchos de los mitos que existen sobre ellos. Me permito una posible lectura del dato juvenil: la generación socializada bajo la sombra del kirchnerismo, que ha restaurado al clivaje como combustible de la política, tiende a tener una percepción menos commoditizada de la dirigencia política. 
Tabla 2

Acuerdo/desacuerdo con la frase "todos los políticos son iguales" según género, edad, nivel educativo e imagen del Gobierno nacional (en \%)

\begin{tabular}{|c|c|c|c|c|c|c|c|c|c|c|c|}
\hline & \multirow[t]{2}{*}{ Total } & \multicolumn{2}{|c|}{ Género } & \multicolumn{3}{|c|}{ Edad } & \multicolumn{3}{|c|}{ Nivel educativo } & \multicolumn{2}{|c|}{$\begin{array}{c}\text { Imagen } \\
\text { del } \\
\text { Gobierno } \\
\text { nacional }\end{array}$} \\
\hline & & Masc. & Fem. & $\begin{array}{c}16 \mathrm{a} \\
30\end{array}$ & $\begin{array}{c}31 a \\
50\end{array}$ & $>50$ & Bajo & Medio & Alto & Pos. & Neg. \\
\hline Acuerdo & 39 & 39 & 38 & 32 & 41 & 43 & 48 & 38 & 28 & 26 & 50 \\
\hline Desacuerdo & 54 & 56 & 53 & 60 & 54 & 49 & 42 & 56 & 68 & 68 & 46 \\
\hline $\mathrm{Ns}-\mathrm{Nc}$ & 7 & 5 & 9 & 8 & 5 & 8 & 10 & 6 & 4 & 6 & 4 \\
\hline
\end{tabular}

Fuente: elaboración propia en base a la "Encuesta Cultura Política en Argentina” (Ibarómetro-Flacso, 2014).

\section{La cultura política en movimiento: evolución reciente}

Al comienzo del trabajo hice alusión a un proceso de politización que se estaría operando en la sociedad argentina, donde encuentro una clave insoslayable para comprender el ecosistema cultural de la Argentina reciente. Los datos expuestos hasta el momento permiten caracterizar la sociedad argentina como un colectivo politizado, pero aún queda una deuda pendiente: demostrar que se trata de un proceso. La expresión proceso es ambiciosa y su demostración exigiría, seguramente, datos para un período de tiempo más largo que el comprendido por nuestras mediciones. De cualquier manera, disponemos de datos a través de los cuales se ponen de manifiesto diversas tendencias que confluyen en un mismo sentido y, que si no acreditan, al menos sugieren la existencia de un 
proceso dinámico y de mayor alcance que el que puede congelar una fotografía.

Los siguientes gráficos ilustran la evolución reciente de cuatro de los indicadores de politización abordados más arriba. Una aclaración: si bien los datos anteriores son de alcance y de representatividad nacional, los siguientes están restringidos al Área Metropolitana de Buenos Aires (AMBA), dado que las tres primeras mediciones -2010, 2011 y 2012- tuvieron ese recorte geográfico. Pese a esta limitación, podrá advertirse que la evolución recorrida por los indicadores es elocuente respecto de las tendencias referidas. A su vez, los datos del AMBA recogidos en 2014 prácticamente se superponen con los datos nacionales compartidos, de manera que además de revelar el sentido de las variaciones en el tiempo, los gráficos permiten deducir que no existen grandes diferencias en materia de politización entre el AMBA y el resto del país.

Los indicadores, cuya evolución reciente será examinada, son "hábitos de politización subyacente" -incidencia de "conversar sobre política" e "intentar convencer a conocidos sobre opiniones políticas" - e indicadores de eficacia política interna (EPI), concernientes al empoderamiento subjetivo, cívico de los ciudadanos. 


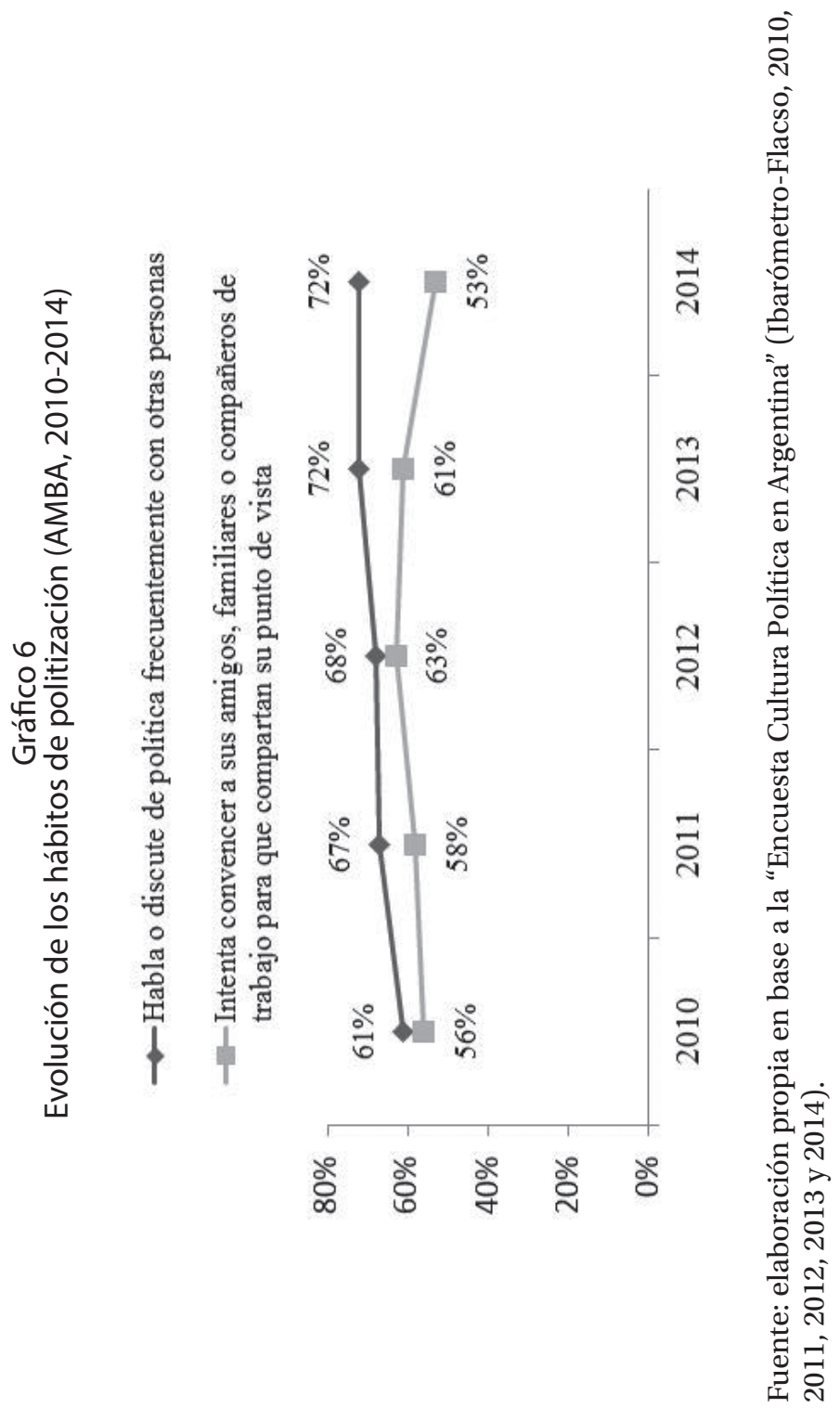




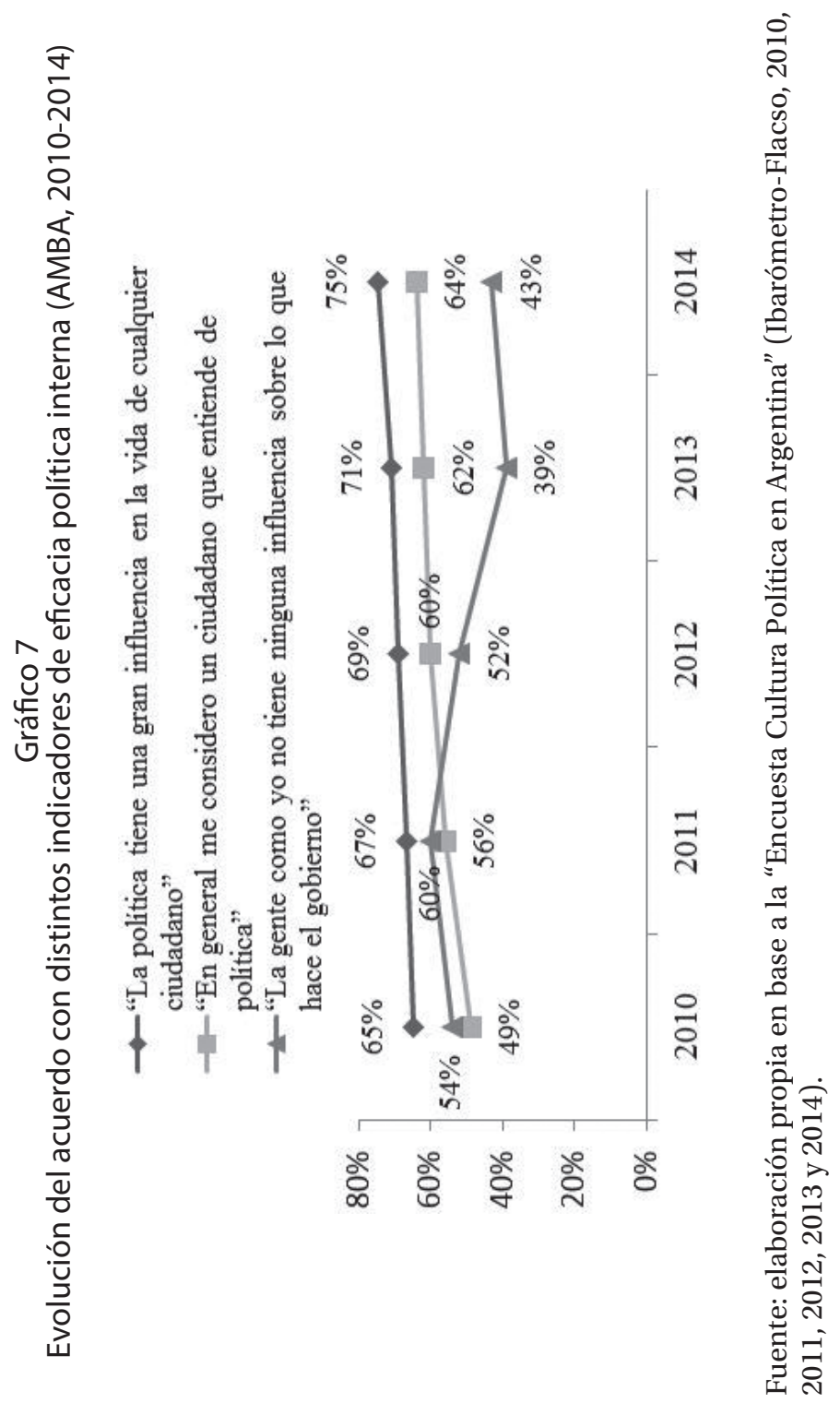


El hábito de conversar sobre política gana terreno entre los argentinos; desde el punto de partida de las mediciones trepa más de 10 puntos: pasa de un $61 \%$ a un $72 \%$ de residentes en AMBA que declara hablar sobre política. Por su parte, la "actitud militante" sufre variaciones menos pronunciadas: se mantiene en un umbral similar entre la primera medición, $56 \%$, y la última ola, $53 \%$.

Los indicadores de EPI dejan huellas muy visibles respecto a cuál es la dirección de sus pasos: crecen sustancialmente los dos indicadores directos de empoderamiento cognitivo, mientras que la variable que mide la impotencia ciudadana es la única que manifiesta una evolución descendente. La idea de que no podemos incidir en la esfera política recolecta muchas menos adhesiones en 2014 que en 2010: cae del $54 \%$ al $43 \%$.

\section{Consideraciones finales: en busca de las causas}

A contramano de la desafección política contemporánea reiteradamente diagnosticada, se observa entre los argentinos un sostenido proceso de politización. La politización, o su reverso la desafección ciudadana, es un rasgo central de la cultura política de una sociedad. Tal es así, que las investigaciones sobre cultura política de los españoles suelen destacar al "pasotismo" (anemia cívica) como la actitud dominante de sus ciudadanos ante la política ${ }^{9}$ (Benedicto y Morán, 1995). En relación con su origen, los trabajos dirigidos a medir y a analizar actitudes políticas subrayan que la socialización secundaria y la herencia familiar operan como factores explicativos del tipo

Resultará interesante conocer si existen diferencias a partir de las movilizaciones del 15M y de la irrupción de Podemos en la escena política española. 
de actitudes políticas desplegadas por los ciudadanos. En este sentido, la constelación actitudinal que estructura el vínculo de un sujeto con la esfera pública se iría conformando principalmente desde el espacio privado y en el marco de cierta endogamia sociológica: familia, colegio y grupo de pares.

Regresemos a la Argentina, cuya politización no es un rayo en un cielo estrellado ya que anida en su historia política, en virtud de lo cual hablé en distintos momentos de "(re)politización". De cualquier manera, los indicios más sugerentes para pensar la actual efervescencia los encuentro en el kirchnerismo y sus efectos ambientales. En cada etapa histórica es posible reconocer cierta correspondencia entre el clima cultural que transpira una sociedad y el rumbo político y los liderazgos más sobresalientes de ese período.

Desde esta perspectiva, podría pensarse que algunas características constitutivas del kirchnerismo han actuado como un agente politizador de la sociedad argentina. Identifico dos vías principales a través de las cuales han operado estos efectos ambientales del kirchnerismo. Sin pruebas que respalden mi afirmación, esbozo una propuesta explicativa: estas vías constituyen dos de las principales causas del proceso de politización del que hemos hablado y que ha anidado fundamentalmente en el espacio público. A tales vías, causas, las llamaré "el derrame simbólico" y "el efecto clivaje".

El derrame simbólico. Las reflexiones sobre cultura política nacieron atravesadas por una serie de debates. Uno de los más importantes es aquel respecto a si la cultura política cambia o es, por el contrario, un dato inmutable de las sociedades. Después de las críticas recibidas por el trabajo fundacional, The Civic Culture, donde la cultura política aparecía esencializada, surgió un posterior consenso que concibe la cultura política como un fenómeno abierto al cambio (Botella, 1997). Como todo, la cultura 
política también cambia pero no lo hace con la intermitencia que distingue a la opinión pública. El debate entre fenómeno expuesto al cambio vs. esencia inmutable fue sustituido por la búsqueda de las causas que explican las variaciones. La lista de factores capaces de apalancar trasformaciones en la cultura política es larga y diversa. Una larga lista de investigadores fue poniendo el acento en aspectos diferentes: procesos de modernización, efectos de la innovación tecnológica, el desarrollo socioeconómico, recambios generacionales (Inglehart, 1988). Todos estos enfoques representaron aportes muy valiosos e insoslayables para pensar el cambio, pero fue a través de John Zaller que encontré el planteo más oportuno para invocar aquí. Zaller analizó detenidamente la evolución de las actitudes raciales de los norteamericanos blancos con el objetivo de demostrar de qué manera alteraciones en los discursos de mayor visibilidad pública de las élites pueden conducir a cambios en el conjunto agregado de actitudes de la sociedad (Zaller, 1992). Veamos.

En 1944 sólo el 45\% de los encuestados blancos creía que negros y blancos debían tener idénticas oportunidades laborales mientras que en 1972 el 97\% adhería a esa convicción de equidad. En sintonía, la pregunta por si negros y blancos debían estudiar en los mismos colegios recibía el $32 \%$ de las respuestas afirmativas en 1942 y el $90 \%$ en 1982 (Zaller, 1992).

La atención analítica de Zaller está puesta en el discurso de las élites como posible agente promotor de cambios en distintos ingredientes de una determinada cultura política. Éste es el mecanismo al que aludo con la expresión "derrame simbólico", por el cual los discursos de mayor visibilidad en una determinada etapa "contagian" sus principales valores y contenidos hacia abajo. Aplicado a la Argentina reciente, resulta evidente que el discurso kirchnerista ha sido, desde su aparición, un discurso fuertemente reivindicatorio de 
la política, de la militancia juvenil, del rol del Estado y de lo público. Dejo de lado cualquier tipo de consideración u opinión sobre la armonía o el desajuste entre el discurso y la acción de gobierno. Mi interés aquí se limita a enfatizar el efecto performativo del discurso kirchnerista y por lo tanto los efectos culturales que ha tenido su "acción discursiva", cuya consecuencia más notoria ha sido la de re-politizar a un amplio sector de argentinos.

El efecto clivaje. El lenguaje periodístico no convalida sus categorías con la Filosofía o a las Ciencias Sociales; tal vez por ello tenga tanta eficacia. En los últimos años, los medios de comunicación han divulgado una expresión que encerraría la clave de los años kirchneristas. La expresión es "la grieta", dotada de una fuerte evocación visual que proyecta la imagen de una sociedad fracturada. Desde el punto de vista teórico, la tesis implícita en el concepto de grieta es muy débil. Según la "teoría de la grieta", la sociedad argentina habría vivido en un estado de armonía que luego habría sido interrumpido y desnaturalizado por la irrupción de la política, en cuyo paso abre divisiones artificiales, desune, y amenaza la convivencia social y la unidad de las familias. Más que rebatirla, quisiera reconocer en la teoría de la grieta un síntoma de estos tiempos y no tanto una explicación. La mirada en clave de grieta reconoce la aparición de la política y, en segundo lugar, alude a una fractura que podría mantener cierto aire de familia con la noción, conceptualmente más robusta, de "clivaje".

El kirchnerismo ha restaurado al clivaje como combustible de la política, enraizado en una perspectiva que asocia la política con el desacuerdo y que desconfía de los consensos universales, como mitos que reprimen al conflicto de intereses y que obturan la reparación de desigualdades. Este concepto y modalidad de acción política ha encogido los niveles de "nihilismo político" al promover la consolidación de puntos de vista muy marcados y 
segmentados en torno al clivaje organizador de la política argentina: "kirchnerismo vs. anti-kirchnerismo".

En el curso de los últimos años, asimismo, los gobiernos de Néstor Kirchner y Cristina Fernández han salpicado a la sociedad con debates que nunca habían tenido alcances tan amplios: el rol de los medios, el campo, la Justicia, el género, entre otras discusiones que serán recordadas por mucho tiempo. En general, el kirchnerismo ha planteado tales debates con la intensidad pugilística que distingue a un actor político que se representa a sí mismo en una constante pelea. Esta intensidad y estos debates -enhebrados entre sí bajo la noción de clivaje político como centro de gravedad de la política- explican una porción importante del proceso de politización sobre el que hemos hablado y al que hemos intentado documentar.

\section{Sin red ni datos, una idea final}

La memoria funciona a través de sinécdoques y de metonimias, algunas partes reemplazan al todo e imágenes particulares monopolizan el sentido general de un recuerdo. La representación que nos hacemos de las décadas recientes -incluyo a personas que no las vivieron directamente- transitan un costumbrismo extra-político, en el que sobresalen determinados consumos culturales, televisivos, gastronómicos y acontecimientos deportivos de aquellos tiempos. Los años noventa, con sus productos importados, sus series de televisión y su textura cultural farandulizada. Los años ochenta, por su parte, se nos suelen aparecer con su particular estética, su música y la gesta maradoniana. Desde ya que en ambas etapas, especialmente la alfonsinista, la política estuvo fuertemente presente, pero especialmente para quienes las vivieron de manera directa. Las generaciones que no "vivieron" las dos décadas 
anteriores al actual ciclo no las asocian fundamentalmente con la política sino más bien con la cultura (los ochenta) y el consumo (los noventa).

A diferencia de las dos anteriores, la última década será evocada esencialmente a través acontecimientos y figuras del ámbito político. Del futuro aún no sabemos nada y cuando consigamos conocerlo, ya no será futuro.

\section{Bibliografía}

Almond, G. y Verba, S. (1965). The Civic Culture. Boston: Princeton Univertsity Press.

Anduiza, E. y Bosch, A. (2009), Comportamiento político y electoral. Barcelona: Ariel Ciencia Política.

Benedicto, J. (1997). "Las bases culturales de la ciudadanía democrática en España”, Cultura política. Valencia: Tirant lo Blanch.

Benedicto, J. y Morán, M. L. (1995), Cultura política de los españoles. Un ensayo de reinterpretación. Madrid: Centro de investigaciones Sociológicas.

Botella, J. (1997). "En torno al concepto de cultura política: dificultades y recursos”, Cultura política. Valencia: Tirant lo Blanch.

Capurro, D. y Ramírez, I. (2011), "No todo es pan y manteca. Triunfo kirchnerista y cultura política”, Cuadernos Argentina Reciente, N. ${ }^{\circ}$ 8, pp. 38-41.

Del Castillo, P. y Crespo, I. (1997). Cultura política. Enfoques teóricos y análisis empíricos. Valencia: Titant lo Blanch.

Hirschman, A. O. (1986). Interés privado y acción pública. México D. F.: Fondo de Cultura Económica.

Inglehart, R. (1988), "Cultura política y democracia estable”, Revista Española de Investigaciones Sociológicas, N. 42, pp. 45-66. 
Mora y Araujo, M. (2011), La Argentina bipolar. Buenos Aires: Sudamericana.

Noelle-Neumann, E. (1995), La espiral del silencio. Opinión Pública: nuestra piel social. Barcelona, Paidós.

Page, B. y Shapiro, R. (2013). The rational public. Chicago, The University of Chicago press.

Putnam, R. (2002). Solo en la bolera. Colapso y resurgimiento de la comunidad norteamericana. Barcelona: Galaxia Gutenberg.

Ramírez, I. (2013), "Los medios y el fin de la inocencia”, Revista de la Carrera de Comunicación Social de la Universidad de Buenos Aires, N. ${ }^{\circ}$ 7, pp. 28-33.

Rosanvallon, P. (2007). La contrademocracia: la política en la era de la desconfianza. Buenos Aires: Fondo de Cultura Económica.

Sennet, R. (1978). El declive del hombre público. Barcelona: ediciones península.

Tocqueville, A. de (1963). La democracia en América. México: Fondo de Cultura Económica.

Zaller, J. (1992). The nature and origins of mass opinions. New York: Cambridge University Press. 